\section{Atopic Dermatitis in Cameroon: Quality of Life and Psychiatric Comorbidities among Affected Children and Adolescents Running Head: Atopic Dermatitis and Psychiatric Impairments}

Emmanuel Armand

Kouotou ${ }^{1,2,3}$

Jobert Richie Nansseu ${ }^{3}$, Erna Gaëlle Tuekam Tuekam4 Sandra A Tatah ${ }^{2,3}$, Isidore Sieleunou ${ }^{5}$ and Elie Claude Ndjitoyap $\mathrm{Ndam}^{3}$

1 Biyem-Assi District Hospital, Yaoundé, Cameroon

2 Yaoundé University Teaching Hospital, Yaoundé, Cameroon

3 Faculty of Medicine and Biomedical Sciences, University of Yaoundé I, Yaoundé, Cameroon

4 Higher Institute of Medical Technologies, Yaoundé, Cameroon

5 School of Public Health, University of Montreal, Montreal, Canada

Results: A total of 53 children were recruited. The median age was 60 months. There were 23 cases of severe AD, 21 of moderate AD and 9 of mild AD. QoL was impaired in $94.3 \%$ of cases, moderate in 20 subjects, high in 8 patients and extreme in 2 patients. QoL of the family was impaired in $88.7 \%$ of cases, moderate in 16 and high in 7 families. The higher the severity of $A D$, the more QoL of patients was impaired $(r=0,475 ; p<0.0001)$, as well as that of families $(r=0,365 ; p=0.007)$. Alteration in patients' QoL was linked with that of families $(r=0.527 ; p<0.0001)$. There were 5 teenagers with mild depression, 2 with mild anxiety, and 1 with moderate anxiety.

Conclusion: AD alters the QoL of children and their families.

Keywords: Atopic dermatitis; Quality of life; Psychiatric impairment; Children; Cameroon

Abbreviations: AD: Atopic Dermatitis; QoL: Quality of Life.
Corresponding author:

Emmanuel Armand Kouotou

”kouotoea@yahoo.fr or kearm_tosss@yahoo.fr

Dermatologist, Allergologist, Senior Lecturer, Department of Internal Medicine and Specialties, Faculty of Medicine and Biomedical Sciences, University of Yaoundé I, Yaoundé, Cameroon.

Tel: $+237242111999 /+237696955083$ $/+237679844360$

\title{
Background
}

Atopic dermatitis (AD) is a chronic, relapsing inflammatory skin disease which may be associated with respiratory allergies such as asthma or allergic rhinitis [1]. AD begins in early childhood, period during which the most severe forms are seen. Pediatric incidence of this disease varies from $2.8 \%$ to $20 \%$ [2-5].

The cardinal signs of $A D$ are pruritus, xerosis and evolution with repeated flares [6]. The intensity of pruritus causes patients to regularly scratch themselves [7]. When the pruritus is very

Citation: Kouotou EA, Nansseu JR, Tuekam EGT, et al. Atopic Dermatitis in Cameroon: Quality of Life and Psychiatric Comorbidities among Affected Children and Adolescents Running Head: Atopic Dermatitis and Psychiatric Impairments. Clin Pediatr Dermatol. 2017, 3:1. 
intense, it can cause difficulties in falling asleep or lead to repetitive awakenings, resulting in an irritability which sustains the stress caused by the disease; eventually, quality of life (QoL) of children and parents may deteriorate [8]. Several studies have found a significant association between severity of $A D$ and $Q o L$ $[9,10]$. Although subjects with AD show no specific psychological disturbances, sometimes they are anxious and the disease interferes in their relationships with their entourage, which can lead to withdrawal [11]. The impact of AD on QoL is an important element often overlooked by practitioners. Direct effects such as sadness, inertia and depression are often seen in children who have the condition [12]. However, impaired QoL can integrate the guilt of parents for not being able to control flares in their children and sibling rivalry because the focus is more on the ill child. This may be a constant source of psychological stress for the entire family.

Very little data is available on the QoL of patients with $A D$ in Africa. In Cameroon, particularly (a sub-Saharan African country), there is to date and to the best of our knowledge no study on this subject. It is in this context that we conducted the present study with the aim of assessing the impact of $A D$ on QoL of patients and their families, and investigate the existence of psychiatric comorbidities (depression, anxiety).

\section{Methods}

This was a cross-sectional study conducted over a period of 3 months from February to May 2015 in five health facilities in the city of Yaoundé that offer consultations in dermatology. These were: the Yaoundé Central Hospital, the Yaoundé Military Hospital, the Yaoundé University Teaching Hospital, the BiyemAssi District Hospital and the Elig-Essono Sub-Divisional Hospital.

Any child aged between 0 and 16 years seen for dermatology consultation, diagnosed with $A D$ by a dermatologist and whose parent/guardian had given informed consent were included in the study. All patients with other skin diseases preventing a proper estimation of the severity of AD or whose parent/guardian refused to participate were not included.

\section{Data Collection}

After obtaining ethical clearance and authorizations from the directors of the various sites of the study, all aspects of the study were presented to the parents/guardians of children with $A D$ who met our inclusion criteria. We used a questionnaire to collect information, namely demographics (age, gender, level of education of the child and parents, type of home, level of cleanliness and environment, profession of parents, size of the family), history of the disease, and family history. During the physical examination, the dermatologist assessed the severity of $A D$, while the psychiatric assessment and evaluation of the patient's and family's QoL were done at the end of the consultation. These assessments were conducted using preestablished and standardized scores and scales.

\section{Assessment of the severity of AD (Clinical score of AD)}

Atopic Dermatitis scoring (SCORAD) is a measurement system scaled from 0-103 [13] that enables assessment of the severity of $A D$. According to this index, $A D$ is classified into mild, moderate and severe for indices between "0-24", "25-50" and "51-103" respectively.

\section{Assessment of the patient's QoL}

The Infant's Dermatitis Quality of Life index (IDQoL) [14] is a QoL scale specific to AD which evaluates QoL of children aged 0-4 years. Parents answer questions about the child's illness over the course of the week before consultation. This scale consists of 10 items and each item is scored from 0 to 3 . The IDQoL is calculated by adding the score of each question. The total varies from 0 to 30 points; the higher the score, the more QoL is impaired.

The Children's Dermatology Life Quality Index (CDLQI) is a scale of QoL less specific to AD but that evaluates QoL in children aged 4 to 16 years. Patients answer questions about their illness during the previous week. It consists of 10 elements and each element is rated 0 to 3 . In our study, the questionnaire was given to children 5 to 16 years. The CDLQI is calculated by adding the score of each question; this score ranges from 0 to 30 points.

The patient's QoL, regardless of the scale used was either unaltered for a score between "0-1", or weakly, moderately, highly or extremely impaired for scores between "2-6", "7-12", "13-18" and $\geq 19$ respectively.

\section{Assessment of the patient's family QoL}

The Dermatitis Family Impact (DFI) is a QoL scale specific to AD which assesses the changes caused by the patient's AD on the life of his/her family. It is completed by the parent or guardian. It includes 10 items, each rated from 0 to 3 . In the same way as the patient QoL, family QoL is either unaltered (score 0-1), weakly (score 2-6), moderately (Score 7-12), highly (13-18 score), or extremely impaired (score $\geq 19$ ).

\section{Psychiatric Evaluation of Adolescents}

The Patient Health Questionnaire 9 (PHQ-9) [15] is a 9-point self-evaluation scale for diagnosis of depression. Each item is rated from 0-3 and the score ranges from 0 to 27 . For a score between "0-4", depression was considered non-existent; it was considered mild, moderate, moderately severe and severe for scores between "5-9", "10-14", "15-19" and "20-27" respectively.

The Generalized Anxiety Disorder 7 (GAD-7) [16] is an evaluation scale for anxiety with 7 items, and is considered a useful screening tool for generalized anxiety disorder. Each item is scored on a scale of $0-3$ and the score ranges from 0 to 21 . For a score between "0-4" the patient was considered "not anxious". Furthermore, anxiety when it existed, was considered mild, moderate or severe for scores between "5-9", "10-14" and "15-21" respectively.

\section{Statistical analyses}

Data were encoded and entered with Microsoft Excel 2007 software and SPSS Version 20.0 (IBM Inc., Chicago, Illinois, USA) served for analysis. Results are presented as percentages for categorical variables, and median (interquartile range IQR) for quantitative variables. The Pearson's Chi-squared test was used to compare proportions, while non-parametric tests were used 
for quantitative variables comparisons. The Spearman correlation test was used to measure the association between quantitative variables. The significance level was set at $p<0.05$.

\section{Ethical considerations}

Before commencing the study, ethical clearance was obtained from the Institutional Ethics Committee of Research for Human Health of the University of Douala registered under number CEI-UD/244/02/2015/T. In addition, authorizations were issued by the administrative authorities of the various study sites. The procedures used in this study were consistent with the revised Declaration of Helsinki. All aspects of the study were presented and clearly explained to parents/guardians; their children were included only after obtaining their consent, materialized by signing the informed consent form. We ensured that the confidentiality and anonymity of the information collected were respected. Each participant was provided extensive information based on his concerns and expectations at the time. Each was also handed a health tips sheet to improve knowledge on the disease and the results of ongoing treatment.

\section{Results}

A total of 408 children aged between 0 and 16 years were received for consultation during the study period. In this sample, 147 (36\%) had eczema while 53/147 (36.1\%) suffered from AD and met our inclusion criteria.

\section{Sociodemographic characteristics}

Ages of patients ranged from 2 to 168 months with a median of 60 (30-93) months. There were more female patients $(54.7 \%)$, with a M/F sex ratio of 0.8 (Table 1). Among patients' parents (or escort), 29 (54.7\%) had studied up to the university/college; 39 patients (73.6\%) lived in urban areas, $16(30.2 \%)$ lived with furry pets, and only 15 patients $(28.3 \%)$ always wore cotton clothing (Table 1).

\section{Evaluation of the severity of AD}

The severity of the disease, evaluated by SCORAD ranged from 15.1 to 69 with a median score of 45.1 (35.5-56.5) points. We recorded 23 cases (43.4\%) of mild $A D, 21$ cases (39.6\%) of moderate $A D$, and 9 cases (17.0\%) of severe $A D$ (Table 1$)$. The score distribution was comparable between the different age groups $(p=0.420)$. Similarly, there was no association between the severity of the disease and the place of residence, the modernity of the home, the presence of domestic furry animals, the use of irritating cleaning products and the routine use of cotton clothing: all $p>0.05$ (Table 1 ).

\section{Quality of life of patients and family}

QoL (IDQoL / CDLQI) was impaired in 50 patients (94.3\%), impairment ranging from low to extreme (Figure 1). QoL scores ranged from 1 to 21 with a median of 7 (3.5-9.5) points. In $88.7 \%$ of cases, the QoL of the family (DFI) was impaired: impairment was low in 24 (45.3\%) families, moderate in 16 (30.2\%) families, and great in 7 (13.2\%) families; no extreme impairment was recorded (Figure 2). DFI scores ranged from 0 to 18 with a median of 6 (3-9) points.

\section{Quality of life and AD severity}

There was a positive and statistically significant association between disease severity and the QoL of patients: as AD severity increased, so did the level of QoL impairment ( $r=0.475 ; p<0.0001$ ). Contrariwise, there was no association between QoL and patients' age $(r=0.057 ; p=0.689)$, and even less between the severity of $A D$ and age $(r=-0.180 ; p=0.198)$. We found a positive and statistically significant association between $A D$ severity and QoL of patients' families: $r=0.365 ; p=0.007$. There was no association between the patient's age and the QoL of his/her family ( $r=-0.237 ; p=0.088)$. Furthermore, the more the patient's QoL was impaired, so was that of the family $r=0.527 ; p<0.0001$.

\section{Psychiatric evaluation}

Presence of depression and anxiety were sought only in adolescents (aged 10-16 years), that is 8 of our 53 patients. We found mild depression in 5 patients (62.5\%), mild anxiety in 2 adolescents (25\%), and moderate anxiety in one patient (12.5\%).

There was no relationship between depression and anxiety $(r=0.638 ; p=0.089)$. Similarly, there was no association between the severity of $A D$ and depression $(r=0.311 ; p=0.453)$ and anxiety $(r=0.366 ; p=0.373)$. The relationship between age and depression $(r=0.655 ; p=0.078)$ and anxiety $(r=0.393 ; p=0.336)$ was not significant. There was a significant relationship between family's QoL and patients' anxiety ( $r=0.767 ; p=0.026)$, which was not the case with depression $(r=0.510 ; p=0.196)$.

\section{Discussion}

At the end of this study which included 53 patients with $A D$, the median score of disease severity was 45.1 points with mild $A D$ in $43.4 \%$ of cases, moderate in $39.6 \%$, and severe $A D$ in $17 \%$ of cases. QoL of patients was impaired in $94.3 \%$ of cases, and that of the family in $88.7 \%$ of cases. The higher the severity of the disease, the more QoL of patients or their families was affected; the QoL of patients and their families evolved in the same direction. Clearly, this study shows that $A D$ significantly alters the QoL of children and adolescents who suffer from the condition as well as that of their families, prompting the need for medical and psychological care.

The number of patients decreased with age groups: $49 \%$ aged $0-4$ years, $35.9 \%$ between $5-9$ years, and $15.1 \%$ of $10-16$ years. This can be explained by the fact that the incidence of $A D$ decreases gradually as the child grows older [17].

Patients in our study mostly had severe AD (43.4\%), especially those aged 0 to 4 years. This is higher than the $23.3 \%$ of cases with severe $A D$ found by Monti et al. in a study of 60 Italian children. This difference could be explained by diagnostic and therapeutic errors given that more often, parents of children with $A D$ will initially consult a general practitioner or a pediatrician rather than a dermatologist. Due to inappropriate management, the disease becomes chronic. It is usually at this stage that the dermatologist will be sought.

We found that QoL was impaired not only in the vast majority of children (94.34\%) but also of families (88.7\%). This result corroborates the assertion that the entourage also endures the 
Table 1 Characteristics of the study population and severity of AD.

\begin{tabular}{|c|c|c|c|c|c|}
\hline \multirow[b]{2}{*}{ Variable } & \multirow{3}{*}{ Number (\%) } & \multicolumn{3}{|c|}{ Severity of AD (SCORAD score) } & \multirow{2}{*}{$p$ value } \\
\hline & & Mild AD & Moderate AD & Severe AD & \\
\hline Age (years) & & $N(\%)$ & $N(\%)$ & $N(\%)$ & 0.886 \\
\hline $0-4$ & $26(49.1)$ & $3(5.7)$ & $11(20.8)$ & $12(22.6)$ & \\
\hline $5-9$ & $19(35.8)$ & $4(7.6)$ & $7(13.2)$ & $8(15.1)$ & \\
\hline $10-16$ & $8(15.1)$ & $2(3.8)$ & $3(5.7)$ & $3(5.7)$ & \\
\hline Parent's/Tutor's level of education & & & & & 0.89 \\
\hline Primary & $6(11.3)$ & $1(1.9)$ & $2(3.8)$ & $3(5.7)$ & \\
\hline Secondary & $18(34.0)$ & $2(3.8)$ & $7(13.2)$ & $9(17.0)$ & \\
\hline University/College & $29(54.7)$ & $6(11.3)$ & $12(22.6)$ & $11(20.8)$ & \\
\hline Residence & & & & & 0.841 \\
\hline Urban area & $39(73.6)$ & $7(13.2)$ & $16(30.2)$ & $16(30.2)$ & \\
\hline Rural area & $14(26.4)$ & $2(3.8)$ & $5(9.4)$ & $7(13.2)$ & \\
\hline Modern house & & & & & 0.726 \\
\hline Yes & $42(79.3)$ & $8(15.1)$ & $16(30.2)$ & $18(34.0)$ & \\
\hline No & $11(20.7)$ & $1(1.9)$ & $5(9.4)$ & $5(9.4$ & \\
\hline Presence of furry animals & & & & & 0.189 \\
\hline Yes & $16(30.2)$ & $4(7.5)$ & $16(30.2)$ & $17(32.1)$ & \\
\hline No & $37(69.8)$ & $5(9.4)$ & $5(9.4)$ & $6(11.4)$ & \\
\hline Use of irritating home detergents & & & & & 0.357 \\
\hline Yes & $47(88.7)$ & 9 (16.9) & 19 (35.9) & $19(35.9)$ & \\
\hline No & $6(11.3)$ & $0(0.0)$ & $2(3.8)$ & $4(7.5)$ & \\
\hline Use of cotton clothing & & & & & 0.898 \\
\hline Yes & $15(28.3)$ & $2(3.8)$ & $6(11.4)$ & $7(13.2)$ & \\
\hline No & 38 (71.7) & $7(13.2)$ & $15(28.2)$ & $16(30.2)$ & \\
\hline
\end{tabular}

\section{IDQoL/CDLQI}

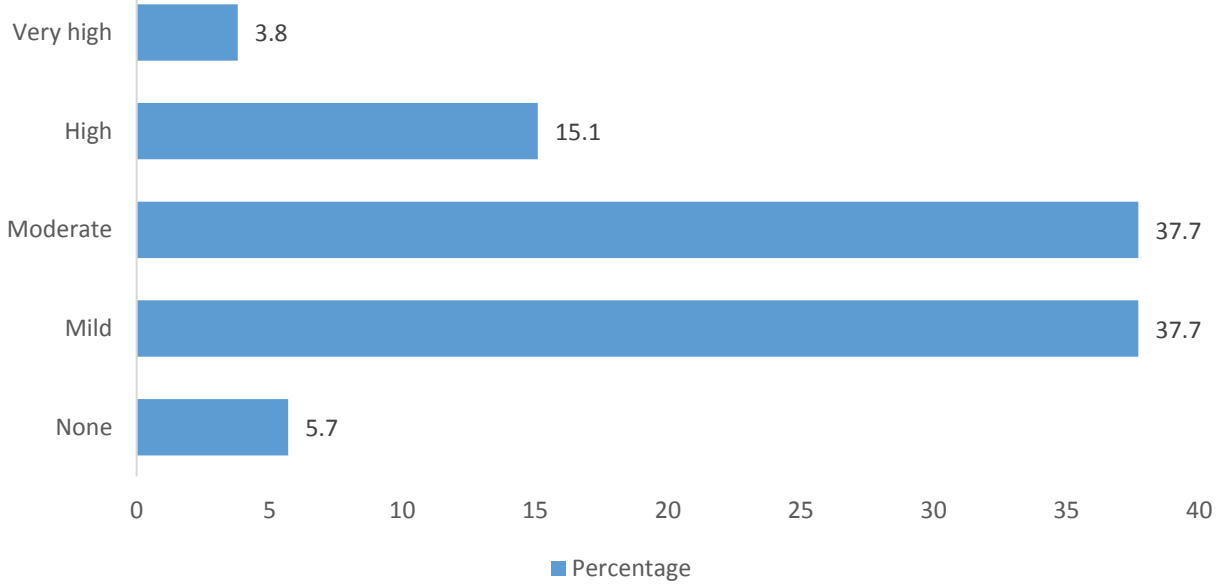

Figure 1 Degrees of impairment of patients' QoL.

effects of $A D$ on the child, resulting from the stress generated by the persistent pruritus and the expenses involved. Our study shows that the most incriminating factor in the deterioration of QoL of the family, after emotional stress, is the financial expenditure. In our context, this could be explained by the low socioeconomic status of families.

Impairment of the QoL of children and families found in our study was equally found by other studies on samples of 42 and
78 children with $A D$ [18]. The association between $A D$ severity and QoL of children and families in our series aligns with previous observations [19-21]. This could be explained by the fact that because of the chronic itching, there is a consequential discomfort and exhibitive lesions which may seriously hamper the QoL of the child as well as that of his/her entourage; the discomfort depends on the intensity of the endured illness. The slight difference observed in the correlations between AD severity and QoL of 


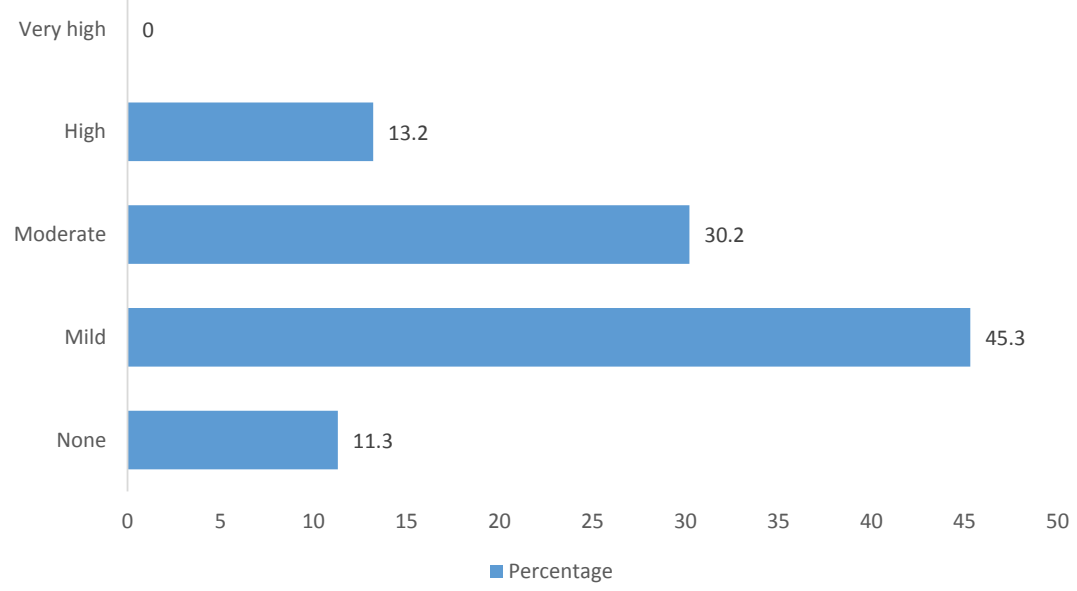

Figure 2 Quality of life of patients' families.

families and that of children ( $r=0,365$ vs 0,475 respectively) could be explained by the fact that the entourage will feel compassion for these ill children and become inconvenienced, but are unable to fully understand what the child feels. Furthermore, in a context of lack of knowledge, the well-looking appearance of the patient sometimes causes families to trivialize this disease. Moreover, some of them think that this disease is "supernatural" and therefore cannot be treated by a doctor.

The significance of the relationship between patient's age and family QoL ( $r=-0.237)$ was borderline $(p=0.088)$. Previous studies have suggested that impaired QoL of the family was related to the child's age. The younger the child is, the more one can get worried, believing the child is less able to manage his/her sufferings. The study conducted by Monti et al. clearly demonstrated a negative association between QoL of the family and the child's age. Ganemo et al. also concluded that QoL of parents was more impaired when the child was younger.

In our study, 5/8 teenagers (62.5\%) suffered from mild depression; we also found a slight anxiety in $2 / 8$ teenagers $(25 \%)$ and moderate anxiety in $1 / 8$ teenagers $(12.5 \%)$. It has been shown that the sensitivity (89.5\%) and specificity $(77.5 \%)$ of the PHQ-9 in adolescents are similar to those of adults, making the PHQ-9 an excellent tool for clinicians and researchers who want to screen adolescents for depression [22]. In our series, a link could be made between pruritus, and anxiety/depression. The importance of pruritus may impede daily activities and interfere with relations with the entourage, resulting in irritability. This irritability maintains a certain level of stress, causing anxiety and even depression. The control of stress and reduction of anxiety or depression will help to reduce outbreaks of AD. Lack of relationship between anxiety or depression and QoL is due to the very small number of patients (adolescents). Nevertheless, we observed that the more the patient was anxious, the more QoL of the family was affected.
Unfortunately, the small sample size could be a flaw to this study. Moreover, the generalization of our results to the entire Cameroonian pediatric population could be questioned, considering that the study was conducted in five health facilities in the city of Yaoundé. Finally, scores and scales used, although standardized, have never been tested and validated in the Cameroonian population.

\section{Conclusion}

$A D$ alters the QoL of children who are affected and that of their families. These QoL are linked to each other and their impairment is more important in cases of severe AD. Assessment of the severity of $A D$ is therefore an important step in the patient's treatment and follow-up. Moreover, complete and efficient management of affected patients must include a psychological aspect.

\section{Ethics approval and consent to participate}

An ethical clearance was granted by the Institutional Ethics Committee of Research for Human Health of the University of Douala. In addition, authorizations were issued by the administrative authorities of the various study sites. All aspects of the study were presented and clearly explained to parents/ guardians; their children were included only after obtaining their consent, materialized by signing the informed consent form.

\section{Consent for Publication}

Not applicable.

\section{Availability of Data and Materials}

Data will be made available on request addressed to any of the co-authors.

\section{Competing Interests}

There is no conflict of interests with regard to this article. 


\section{Funding}

This study benefited from neither source of external funding nor sponsorship.

\section{Authors' Contributions}

EAK and EGTT conceived and designed the study, and collected the data. JRN and EGTT analyzed and interpreted the data. EAK,
JRN and SAT drafted the manuscript. EAK, JRN, EGTT, SAT, IS and ECNN critically reviewed and revised the manuscript. All authors approved the final version of the manuscript.

\section{Acknowledgements}

The authors are grateful to all patients and parents of patients who accepted to participate in this study. 


\section{References}

1 Hay WW, Lewin MJ, Sondheimer JM, Robin R (2008) Current Pediatric Diagnosis and Treatment. 19th edn. McGraw Hill, USA.

2 Guerrero D, Georgescu V, Decoster CJ, Sattler U (2012) Interêt de l'eau thermale d'Avène dans la prise en charge de la dermatite atopique. Press Therm Climat, p: 36.

3 https://www.youtube.com/watch?v=erQxMHbbL98

4 Onunu AN, Eze EU, Kubeyinje EP (2007) Clinical profile of atopic dermatitis in Benin City, Nigeria. Nig J Clin Pract 10: 326-329.

5 Ukonu BA, Eze EU (2012) Pattern of Skin Diseases at University of Benin Teaching Hospital, Benin City, Edo State, South-South Nigeria: A 12 Month Prospective Study. Global J Health Sci 4: 3.

6 Sabatiello M (2014) Dermatite atopique: prise en charge diagnostique et thérapeutique (implication des pneumallergènes et des allergènes alimentaires).

7 Marcoux D (2004) La dermatite atopique chez l'enfant comment maximiser la réponse aux traitements. Le Médecin du Québec 39: 37-42.

8 http://www.neurodermitis-info.ch/fr

9 Monti F, Agostini F, Gobbi F, Neri E, Schianchi S, et al. (2011) Quality of life measures in Italian children with atopic dermatitis and their families. Ital J of Pediatr 37: 59.

10 Alvarenga TM, Caldeira AP (2009) Quality of life in pediatric patients with atopic dermatitis. Soc Brasil Pediatr 85: 415-420.

11 Koeppel MC (2005) Dermatite Atopique. Enc Med Chir, pp: 1-33.

12 Kitchin O, Masekela R, Moodley T, Green R (2010) The value of pimecrolimus in improving quality of life of children with severe eczema - an open non-randomised study. SA Fam Pract 52: 69-71.

13 Silny W, Czarnecka-Operacz M, Silny P (2005) The New Scoring System for Evaluation of Skin Inflammation Extent and Severity in Patients with Atopic Dermatitis. Acta Dermato venerol Croat 3: 219-224.

14 Quality of Life (2016) Department of Dermatology, Cardiff University School of Medicine.

15 Rozefort WR, Bélanger H (2012) Des outils diagnostiques et thérapeutiques comment les démêler sans trop se mêler ? Formation continue. Le Médecin du Québec 47: 30-31.

16 Association canadienne d'oncologie psychosociale et Partenariat canadien contre le cancer (2010) Guide pancanadien de pratique: dépistage, évaluation et prise en charge de la détresse psychosociale (dépression, anxiété) chez les patients adultes atteints d'un cancer. pp: 73-74.

17 Fry L (2005) An Atlas of Atopic Eczema. The encyclopedia of visual medicine series. Edition published in the Taylor \& Francis e-Library.

18 Ganemo A, Svensson A, Lindberg M, Wahlgren CF (2007) Quality of Life in Swedish Children with Eczema. Acta Derm Venereol 87: 345-349.

19 Dong HK, Kapsok L, Seong JS, Sun JJ, Hyeon WY (2012) Quality of Life and Disease Severity Are Correlated in Patients with Atopic Dermatitis. J Korean Med Sci 27: 1327-1332.

20 Société française de dermatologie (2005) Prise en charge de la Dermatite Atopique de l'enfant. Ann Dermatol Venerol.

21 Fondation Dermatite Atopique (2015) Lexique de la Dermatite Atopique.

22 Seattle Children's and Group Health (2015) New PHQ-9 screening test evaluates major depression in adults. 